\title{
CADASTRAMENTO DA ARBORIZAÇÃO DO CAMPUS POETA TORQUATO NETO, DA UNIVERSIDADE ESTADUAL DO PIAUÍ - UESPI
}

\author{
REGISTRATION OF THE AFFORESTATION OF THE CAMPUS POETA TORQUATO \\ NETO, FROM THE STATE UNIVERSITY OF PIAUI' - UESPI
}

\begin{abstract}
Roselis Ribeiro Barbosa Machado¹, Dielle Caroline Leite Alves², Anderson Gonçalves da Silva², Alexandra Ribeiro Machado ${ }^{4}$
\end{abstract}

\begin{abstract}
RESUMO
Uma das principais indispensabilidades da atualidade está relacionada à tomada de decisões no planejamento territorial e gestão ambiental. Neste sentido, o objetivo da presente pesquisa foi realizar o cadastramento das árvores presentes no campus Poeta Torquato Neto da Universidade Estadual do Piauí (UESPI), com uso de mapeamento digital e elaboração de um mapa interativo contendo a identificação dos indivíduos arbóreos presentes no campus para o monitoramento da arborização. Para o levantamento das árvores, considerou-se a mesma metodologia e resultados de estudo realizado no ano de 2017 , com averiguação in loco de dados não apresentados no estudo anterior, no entanto necessários a metodologia deste. Para o mapeamento digital das árvores utilizou-se o software Google Earth Pro. O arquivo digital elaborado possibilita a produção, a cada monitoramento, de um novo mapa e arquivo sequencial. O controle e execução de medidas de manejo e monitoramento foi desenvolvido em planilha do programa Excel, com elaboração de um cronograma para a realização deste monitoramento sequenciada todas as suas etapas. Por meio do levantamento realizado, foi possível constatar que o número total de indivíduos arbóreos na área de estudo teve aumento em comparação ao estudo de 2017, que apontou 529 indivíduos no campus, um acréscimo de 73 indivíduos. Foram realizados dez novos plantios na subárea 1 do campus, atendendo-se espaços mais abertos e que necessitavam de maior sombreamento. A pesquisa é uma importante ferramenta para o planejamento da arborização do campus, promovendo melhorias para o bem estar da comunidade acadêmica.
\end{abstract}

Palavras-chave: Árvores urbanas. Geotecnologia. Manejo arbóreo.

\begin{abstract}
One of the main indispensabilities of today is related to decision making in territorial planning and environmental management. In this sense, the objective of the present research was to register the trees present on the Poeta Torquato Neto campus of the State University of Piauí (UESPI), using digital mapping and elaboration of an interactive map containing the identification of the tree individuals present on the campus for afforestation monitoring. For the survey of trees, the same methodology and results of a study carried out in 2017 were considered, with on-the-spot verification of data not presented in the previous study, although the methodology of this one was necessary. For the digital mapping of the trees, the Google Earth Pro software was used. The digital file created allows the production, at each monitoring, of a new map and sequential file. The control and execution of management and monitoring measures were developed in an Excel program spreadsheet, with the elaboration of a schedule for carrying out this monitoring sequentially in all its stages. Through the survey, it was found that the total number of arboreal individuals in the study area increased compared to the 2017 study, which identified 529 individuals on campus, an increase of 73 individuals. Ten new plantings were carried out in sub-area 1 of the campus, given the more open spaces that needed greater shading. Research is an important tool for planning tree planting on the campus, promoting improvements for the well-being of the academic community.
\end{abstract}

Keywords: Urban trees. Geotechnology. Arboreal management.

Recebido em 17.05.2020 e aceito em 13.11.2020

1 Bióloga. Doutora. Professora Associada II - Universidade Estadual do Piauí. Teresina / PI. Email: roselisribeiro@ccn.uespi.br

2 Bióloga. Graduada. Universidade Estadual do Piauí. Teresina / PI. Email: leitedielle@gmail.com

3 Biólogo. Graduado. Universidade Estadual do Piauí. Teresina / PI. Email: andergonsilva2008@hotmail.com

4.Tecnóloga em Gestão Ambiental. Especialista. Instituto Federal do Piauí. Teresina / PI. Email:

alexandraribeiromachado24@gmail.com 


\section{INTRODUÇÃO}

A preocupação com o meio ambiente encontrou-se definitivamente na agenda dos governos e de diversos segmentos da sociedade civil organizada, nas últimas três décadas do século XX (BARBIERI, 2016). Uma das principais indispensabilidades da atualidade está relacionada à tomada de decisões no planejamento territorial e gestão ambiental, e a resolução passa pela delimitação dos mosaicos paisagísticos (BERTRANT; BERTRANT, 2002).

Nas cidades, as paisagens urbanas são o resultado das transformações do homem diante da natureza, em que toda a cobertura vegetal que a compõe é denominada de floresta urbana (BIONDI, 2015). Em relação à arborização urbana, Moraes e Machado (2014), conceitua como um conjunto de vegetações arbóreas naturais ou cultivadas que uma cidade apresenta. Ainda no cenário urbano, a distribuição da vegetação e seus aspectos de qualidade ambiental repercutem nos modos de vida das populações, em especial no que diz respeito à saúde e qualidade de vida. $O$ investimento em espaços verdes, com ampla variedade de elementos naturais, pode promover a redução dos níveis de estresse e fadiga mental, estimular a realização de atividades físicas, permitir e facilitar as interações sociais e auxiliar na prevenção de doenças, além de contribuir para ações comunitárias relacionadas ao cuidado ambiental (ALBUQUERQUE; SILVA; KUHNEN, 2016).

O crescimento das cidades tem provocado a substituição das árvores no ambiente por elementos como a pavimentação e as construções, resultando, deste modo, em uma série de problemas, tais como: impermeabilização do solo, aumento da temperatura local, diminuição da biodiversidade e elevação de danos à saúde (LO CASTRO, et al., 2017). Em cidades com elevadas temperaturas a vegetação exerce um importante papel, Labaki et al. (2011) afirmam que a vegetação em meio urbano, possui um comportamento diferenciado em relação a radiação solar, podendo absorver cerca de $90 \%$ da radiação visível e $60 \%$ da infravermelha.

Os temas relacionados à qualidade ambiental dessas áreas vêm sendo debatidos nos níveis técnicos e científicos. Entre os temas de maior relevância, a vegetação intraurbana ganhou destaque nos últimos anos devido às funções que esta pode exercer na melhoria das condições do ambiente urbano (BARGOS; MATIAS, 2011). No entanto segundo Brandão et al. (2011), a arborização quando é feita sem planejamento e quando realizado por pessoas inaptas pode gerar conflitos. Isso resulta na ocupação do espaço sem conservar adequadamente os espaços verdes, formando um modelo inadequado e complicado para se reverter (SABBAGH, 2011).

A Universidade Estadual do Piauí (UESPI), campus Poeta Torquato Neto, possui sede na área urbana da cidade de Teresina, capital do Estado do Piauí. É uma das três maiores universidades públicas do Estado, compreendendo, este campus, uma grande extensão territorial, diariamente frequentada por discentes, docentes e servidores, além da comunidade da região do entorno. A área apresenta, além de instalações físicas (construídas), espaços 
destinados à vegetação, com variados indivíduos de diferentes espécies botânicas já implantadas e a implantar.

Rasec (2017) identificaram 529 indivíduos arbóreos distribuídos em 46 espécies e 19 famílias botânicas na área do campus acima referido, com uma distribuição desuniforme, áreas abertas à incidência de raios solares e muita incompatibilidade de indivíduos arbóreos com elementos de infraestrutura presentes no meio. Necessitando, portanto, de busca pela compreensão da diversidade dos aspectos do espaço urbano tornando-se uma preocupação para o planejamento e gestão urbana (BARGOS; MATIAS, 2011).

Munido de tais informações o melhor instrumento é aquele que atenda um formato com celeridade, eficácia e interação com público: o mapeamento digital. As metodologias que utilizam a geotecnologia como ferramenta principal vêm se destacando, sendo a alternativa mais viável para se reduzir significativamente o tempo gasto com o mapeamento de áreas (LUPPI, et al., 2015). Softwares que auxiliam em desenhos bidimensionais e tridimensionais como Google Earth Pro, AutoCAD e Revit são também importantes mecanismos para a produção do georreferenciamento.

Faz-se necessário, portanto, pesquisas que apliquem o uso destas tecnologias a arborização, visando não somente a atualização de dados, mas, sobretudo, possibilitando à elaboração de medidas de manejo e monitoramento mais eficazes para tornar as áreas verdes do campus Poeta Torquato Neto cada vez mais exuberantes e agradáveis a presença humana. Sendo assim, o manejo tem a capacidade de atenuar aspectos negativos agregados a essas áreas, sejam eles de ordem paisagística ou ambiental, e de proporcionar melhorias na qualidade de vida de seus habitantes, consistindo então em um instrumento da gestão ambiental (MACÊDO; LISBOA: CARVALHO, 2012).

O objetivo da presente pesquisa foi realizar o cadastramento das árvores presentes no campus Poeta Torquato Neto da Universidade Estadual do Piauí (UESPI), com uso de mapeamento digital e elaboração de um mapa interativo contendo a identificação dos indivíduos arbóreos presentes no campus para o monitoramento da arborização.

\section{MATERIAL E MÉTODOS}

\section{Área de Estudo}

O campus Poeta Torquato Neto da Universidade Estadual do Piauí (UESPI) está localizado na Zona Centro-Norte do Município de Teresina, capital do Estado do Piauí, situandose na Rua João Cabral, № 2.231, bairro Pirajá, ocupando uma área de aproximadamente $130.077,85 \mathrm{~m}^{2}$ (Figura 1). 
Figura 1. Localização do campus Poeta Torquato Neto da UESPI em Teresina, Piauí, Brasil.

Figure 1. Location of the UESPI Poeta Torquato Neto campus in Teresina, Piauí, Brazil.

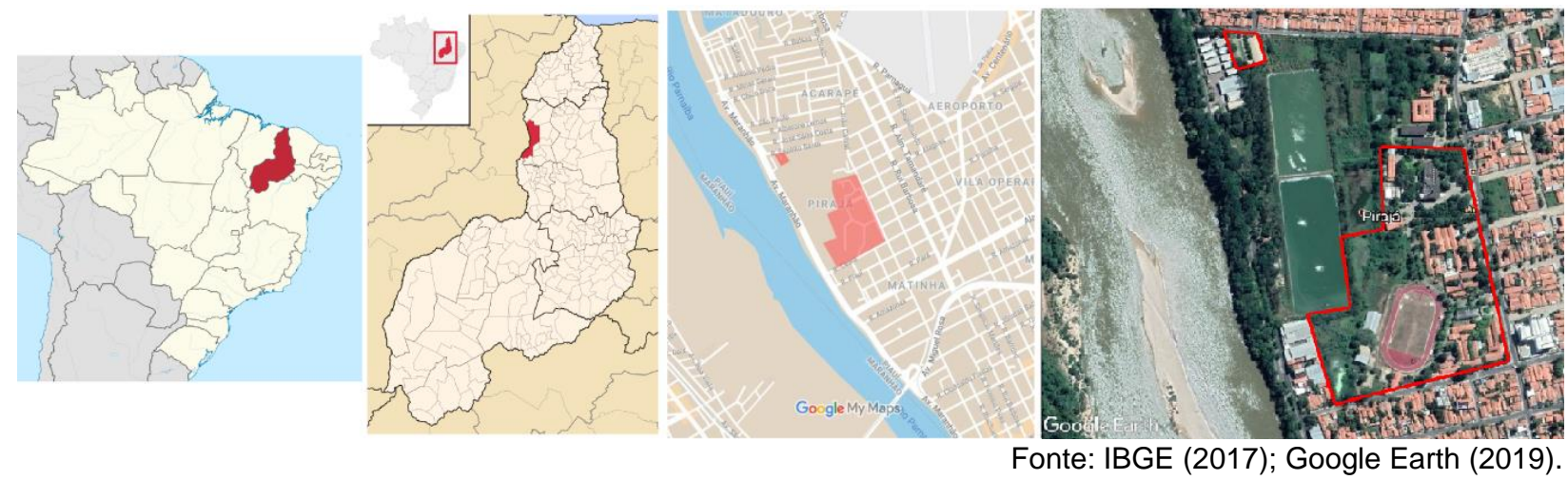

Apresenta o clima C1sA'a' de acordo com a classificação climática de Thornthwaite e Mather (1955), caracterizado como subúmido seco, megatérmico, com excedente hídrico moderado no verão e uma concentração de $32,1 \%$ da evapotranspiração potencial no trimestre setembro-outubro-novembro (BASTOS, 2016), com dois períodos bem definidos, um quente e úmido, entre os meses de janeiro a julho e outro quente e seco, entre os meses de agosto a dezembro (KALLAS, 2008).

\section{Diagnóstico da Arborização}

Para o levantamento das árvores presentes no campus, considerou-se a mesma metodologia e resultados do estudo de Rasec (2017), com averiguação in loco de dados, quando necessários, bem como a identificação das coordenadas geográficas por meio de GPS Garmin Legend Etrex, com correções de posição do Wide Area Augmentation System (WAAS), de cada ponto e indivíduo arbóreo para tornar os resultados o mais próximo possível do real.

Neste estudo a área total do campus foi dividida em seis subáreas (Figura 02), e em cada uma delas, as árvores foram identificadas, utilizando-se uma planilha de campo com os seguintes itens: Localização: registro de um ponto de referência onde a árvore se encontra; Árv. $\mathrm{n}$ :: Número de registro da árvore avaliada; Porte: $\mathrm{P}=$ até $6,0 \mathrm{~m}$ de altura; $\mathrm{M}=6,0$ a $10 \mathrm{~m}$ de altura; $\mathrm{G}$ = acima de $10 \mathrm{~m}$; DC: Diâmetro da projeção da copa, em metro (m) medido com trena, (em copas irregulares tomar o maior diâmetro); EF: Estado fitossanitário ( 0 = árvore morta; 1 = árvore muito doente ou atacada; 2 = árvore apresentando sintomas de doenças ou ataque leve de insetos; 3 = árvore sadia); DP: Danos devido a podas ( $0=$ inexistentes; $1=$ fracos $\mathrm{e}$ recuperáveis; 2 = fortes e irrecuperáveis); VV: Valor visual ( 0 = inexistente; 1 = regular; 2 = bom; 3 = excepcional); MF: Mudança foliar (S ou N); FL: Floração (S ou N); FT: Frutificação (S ou N). Todas as árvores foram fotografadas usando câmera Canon EOS Rebel T6 (Lente EFS 18-55 $\mathrm{mm} /$ Macro $0.25 \mathrm{~m} / 0.8 \mathrm{ft})$. 
Figura 2. Subáreas do campus Poeta Torquato Neto, UESPI, Teresina, Piauí. Figure 2. Sub-areas of the Poeta Torquato Neto campus, UESPI, Teresina, Piauí.

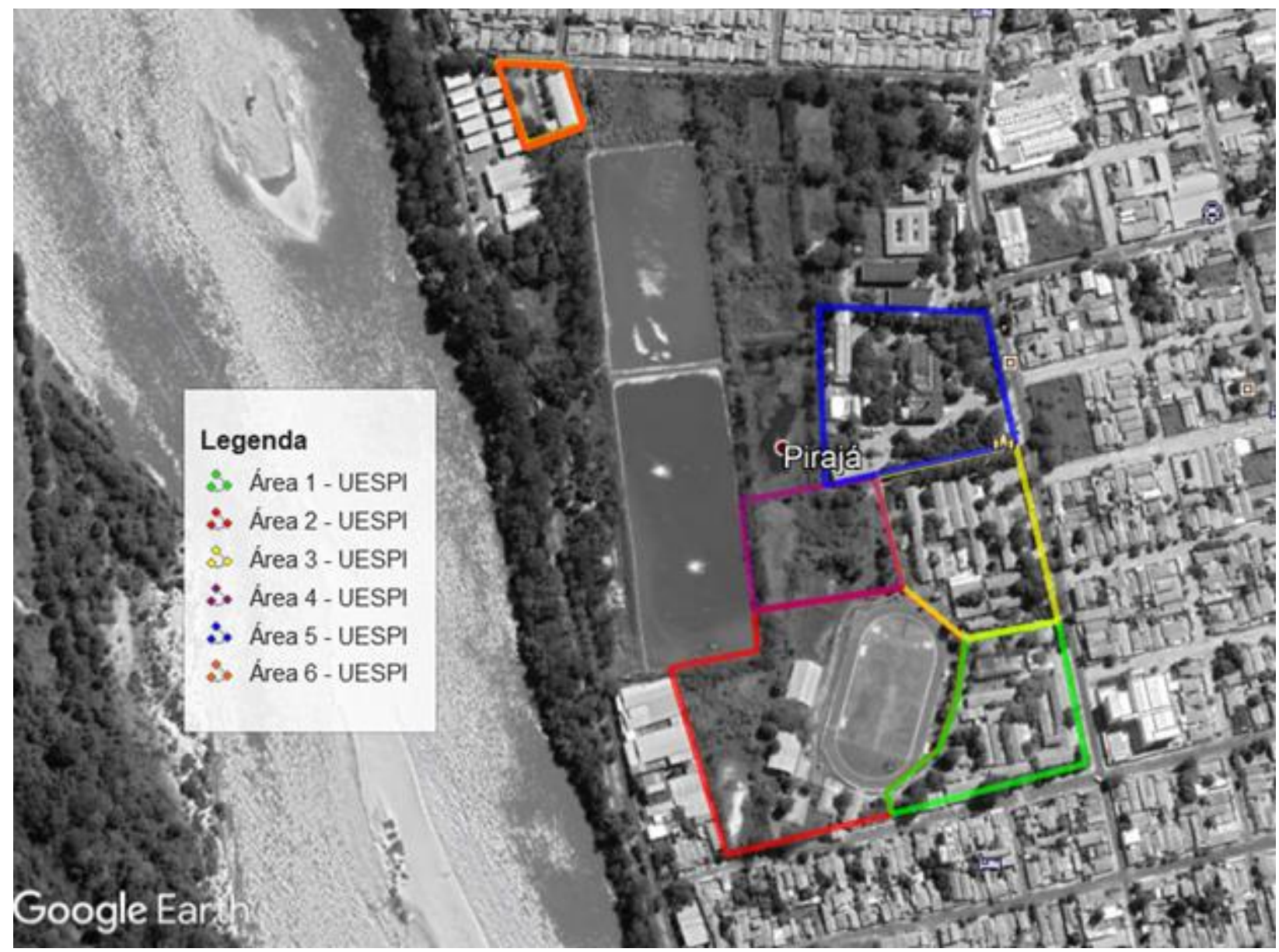

Fonte: Google Earth (2019).

A caracterização morfológica da flora foi realizada utilizando a classificação de Oliveira e Maués (1995), quanto a presença ou não de mudança foliar (árvore desfolhada parcial e total, folhas novas, copa completa com folhas novas, copa completa com folhas velhas), floração (botões florais aparecendo, floração, floração terminada e terminando) e frutificação (frutos novos, frutos maduros e sementes dispersas), no momento do diagnóstico em campo.

\section{Mapeamento Digital Das Árvores}

Os dados arbóreos listados foram utilizados para a criação de um mapa interativo, que compreendeu características científicas, de caráter botânico, abrangendo número de identificação, nome científico e comum, porte, diâmetro da copa, estado fitossanitário, danos devido à poda, valor visual, presença de mudança foliar, flor e fruto e recomendações de manejo, 
além de imagem da árvore inteira e detalhes relevantes. Para o reconhecimento das espécies botânicas no mapa foram utilizadas cores diferentes para cada uma delas.

Os softwares utilizados projetam o mapa em 2D e 3D, facilitando a visualização. Inicialmente o mapa topográfico do campus foi exportado para um dos softwares (AutoCad) para análise e correção da precisão geográfica, em que posteriormente foi transformado em mapa digital (Google Earth - disponível gratuitamente para uso público) em forma de guia em que cada árvore recebeu um número de identificação essencial para o controle e execução de medidas de manejo e monitoramento.

Em razão das vias asfálticas não serem retilíneas, optou-se na ferramenta digital por adicionar caminho ao invés de polígono, em virtude deste perfazer o desenho da área por meio de linhas retas não possibilitando o recurso de movimentação posterior das linhas ajustando-se ao mais próximo do desenho real da via, o que se faz executável por meio da opção caminho (Figura 3). Cada um desses limites recebeu uma cor específica que os diferencia, opção criada no programa pela aba de edição estilo/cor.

Figura 3. Representação da divisão das subáreas utilizando a aba "editar caminho" do programa Google Earth Pro

Figure 3. Representation of the subareas division using the "edit path" tab of the Google Earth Pro program

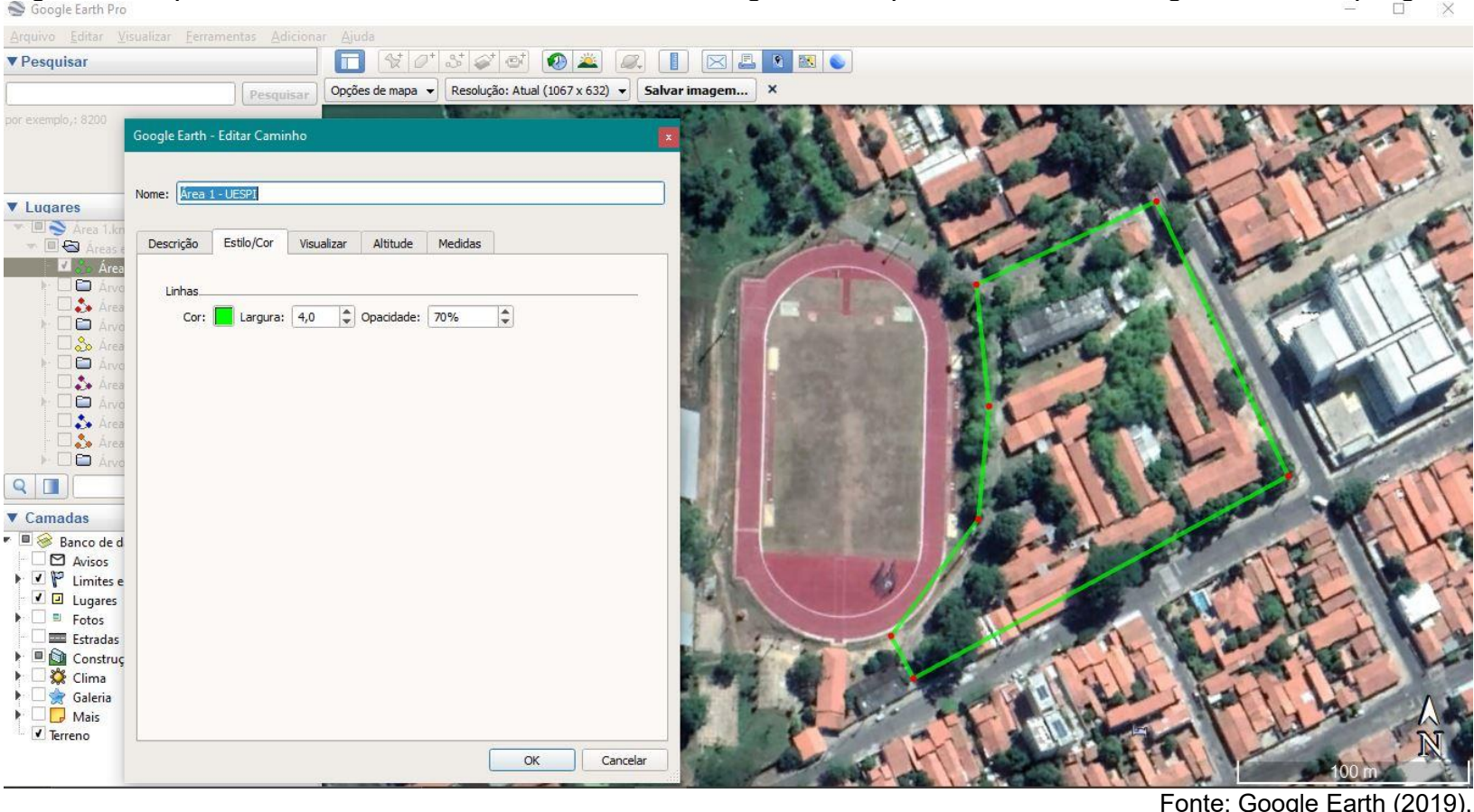

Legenda - Opção caminho desempenhada na produção da divisão da subárea 1 do estudo, identificada pela cor verde por meio da aba de edição estilo/cor do programa.

Com as coordenadas geográficas extraídas in loco, foi possível "adicionar marcador" com o ponto aproximado da localização de cada indivíduo arbóreo no mapa. Na mesma função 
é necessário nomear o ponto, no caso específico cada árvore identificada recebeu uma numeração sequencial.

Ainda foi possível modificar o formato inicial do marcador que se apresenta na forma de alfinete, o escolhido para o mapeamento foi à circunferência que posteriormente agregou-se cores por recurso da aba estilo/cor. Por efeito desta, cada espécie arbórea identificada ganhou uma cor específica, possibilitando o imediato reconhecimento no mapa de onde encontram-se os outros indivíduos da mesma espécie na área de estudo (Figura 4).

Figura 4. Representação de indivíduos da mesma espécie no mapeamento desenvolvido no Google Earth Pro.

Figure 4. Representation of individuals of the same species in the mapping developed in Google Earth Pro.

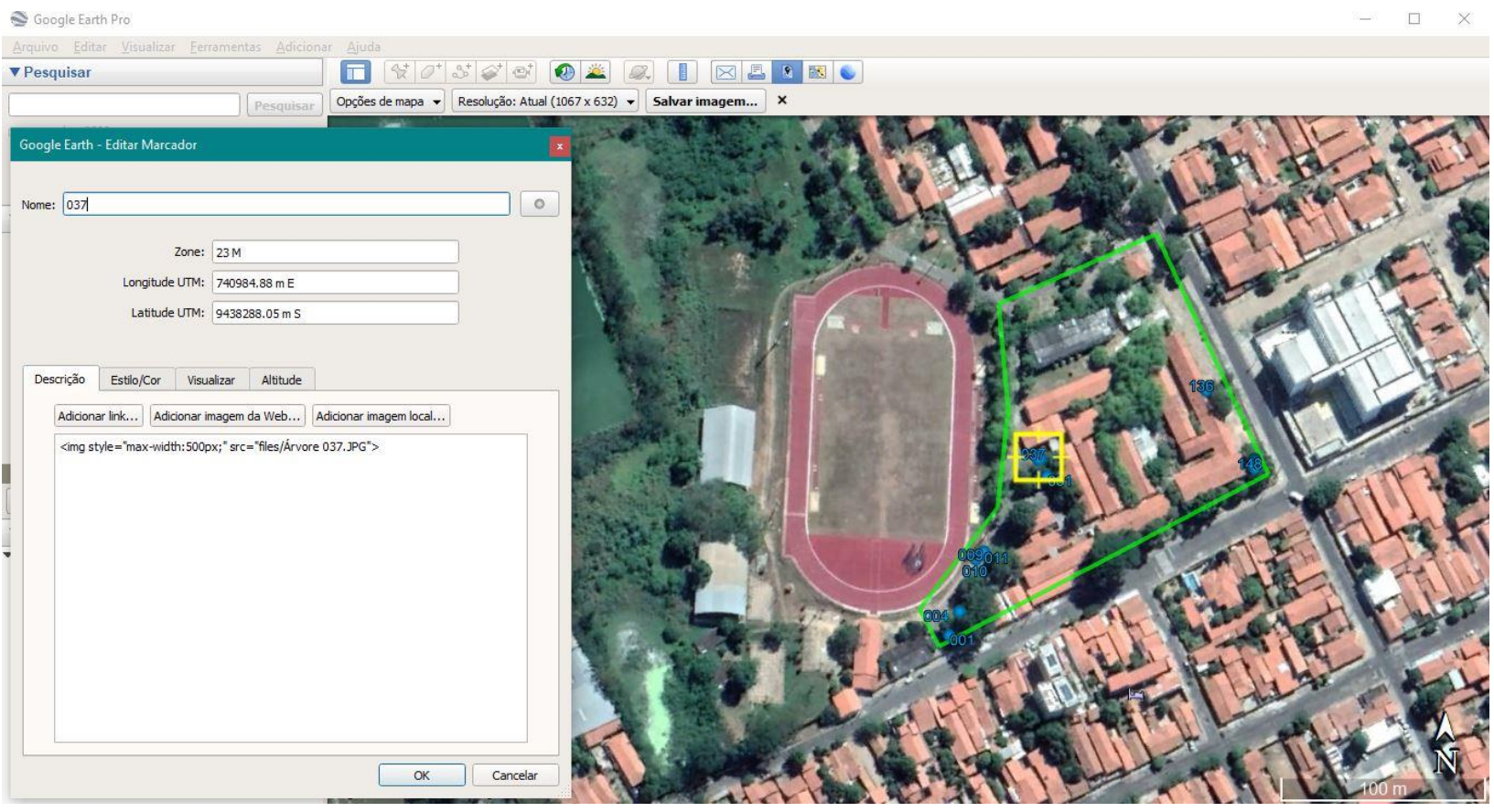

Fonte: Google Earth (2019). Legenda - Marcador em circunferência na cor azul (identificador de espécie) e sua respectiva numeração, coordenada geográfica e descrição com seu registro fotográfico (aba). Na imagem os indivíduos da espécie Pachira aquatica (Mamorana) e sua presença na subárea 1.

Agregando um mecanismo para monitoramento do campus, o ponto identificador do indivíduo arbóreo pode ser representado no mapa por registro fotográfico. Na aba descrição, na opção adicionar imagem local, foi possível inserir uma janela correspondente a cada árvore da subárea 1, composta por imagens (individuo inteiro e detalhes - fotografias da autora), breve caracterização botânica e recomendação de monitoramento, com identificação do mês e ano do registro (Figura 5). 
Figura 5. Representação do registro fotográfico anexado no mapeamento pelo programa Google Earth Pro.

Figure 5. Representation of the photographic record attached to the mapping by the Google Earth Pro program.

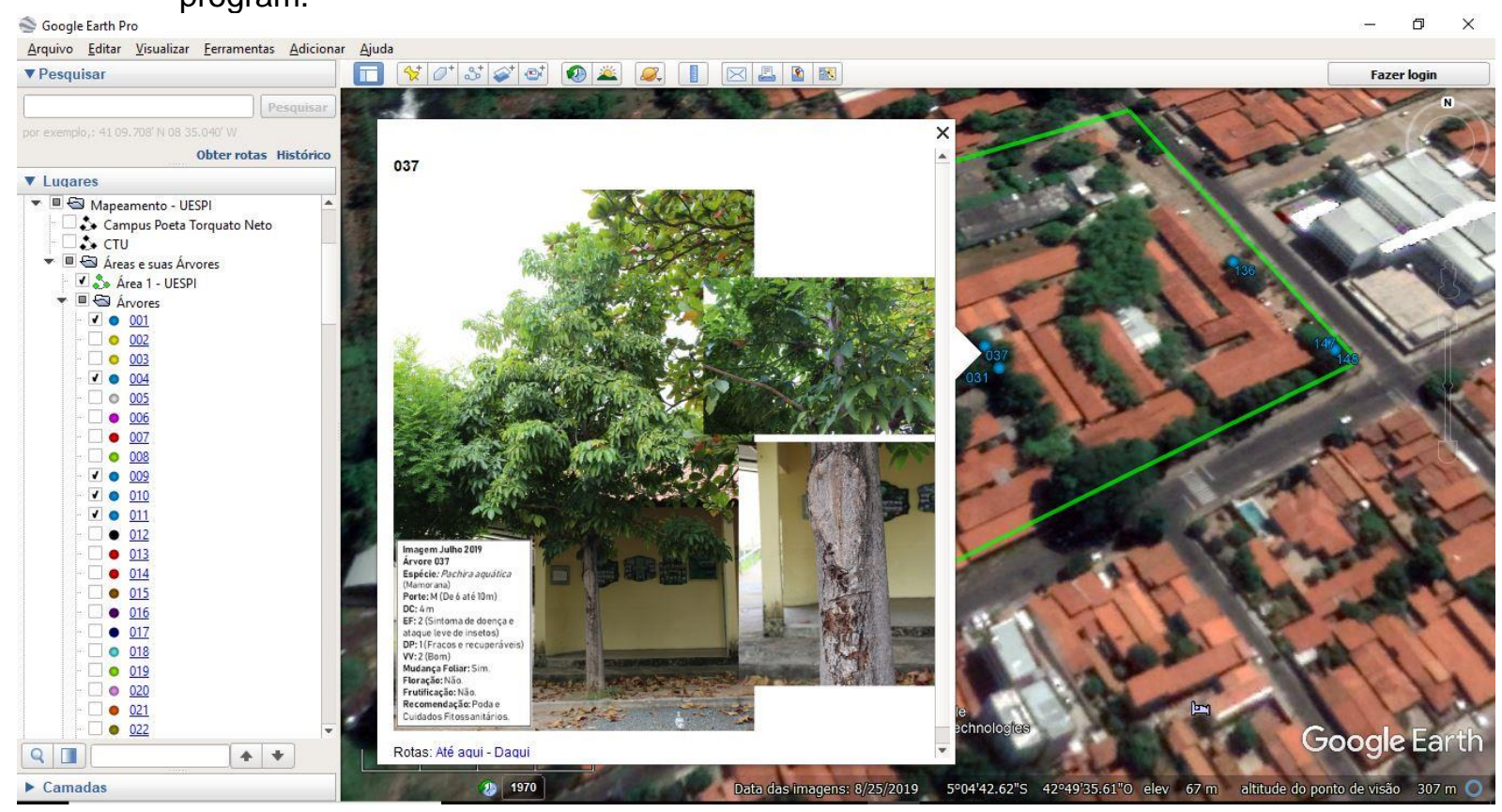

Fonte: Google Earth (2019).

Legenda - Janela correspondente ao indivíduo arbóreo de número 037 (Pachira aquatica) presente na área 1 e sua respectivo registro fotográfico e caracterização.

Para a inserção dos dados nesta janela, são entrepostas as informações colhidas em campo contidas na planilha do programa excel. Tais informações podem ser periodicamente atualizadas, visto que o programa permite salvar o arquivo de trabalho em formato Keyhole Markup Language - kml desenvolvida para uso do programa em linguagem baseada em XML e serve para expressar anotações geográficas. Arquivos com uma grande quantidade de informações são automaticamente zipados para o formato Kmz.

$O$ arquivo pode ser aberto e editado em qualquer computador que contiver o programa Google Earth Pro, possibilitando a produção a cada monitoramento de um novo mapa e arquivo sequencial, o primeiro deles desenvolvido por esse estudo é nomeado como "Mapeamento Digital - UESPI 2019.2". O programa ainda permite a sobreposição de fotos, possibilitando a visualização temporal do indivíduo e os resultados do monitoramento a cada novo registro.

\section{Controle e execução de medidas de manejo e monitoramento}

Foi elaborado um cronograma para a realização do monitoramento, utilizando-se uma Planilha Excel, bem como sequenciada todas as suas etapas, de forma a permitir que periodicamente as áreas verdes da UESPI sejam revitalizadas proporcionando a permanência de uma paisagem natural com vitalidade e beleza agregando mais valor ao campus. 
Para o acompanhamento das medidas de controle e monitoramento das árvores presentes na área de estudo, optou-se pelo uso de uma planilha Excel, desenvolvida posteriormente ao mapeamento botânico. A mesma consta de 13 colunas, que registram os parâmetros utilizados em campo para caracterização de cada indivíduo, além das recomendações desenvolvidas pelo estudo dividida em diagnóstico e resultado (Figura 6).

Figura 6. Planilha Excel da Subárea 1, com os respectivos parâmetros analisados. Figure 6. Excel Spreadsheet of Subarea 1, with the respective parameters analyzed.

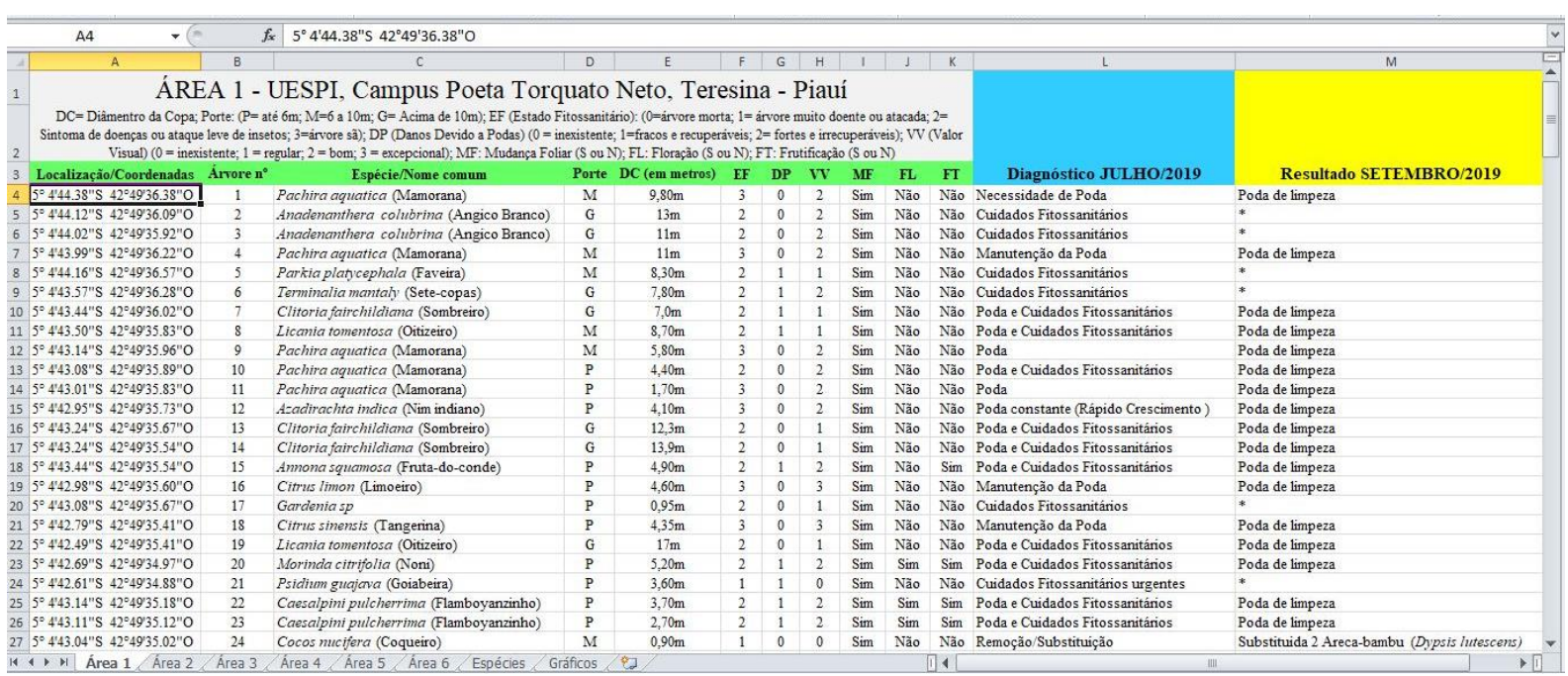

No arquivo Excel, cada subárea mapeada possui uma planilha, que podem ser observadas na aba inferior do arquivo. Para melhor identificação, a linha que separa as informações da planilha e as colunas recebeu a mesma cor dada aos limites das subáreas no programa Google Earth Pro, como a subárea 1 cor verde.

Testou-se, nos meses de julho a setembro de 2019, o monitoramento de uma das subáreas do campus possibilitando a análise do uso da planilha do Excelaqui proposta.

Tendo como base o trabalho de Rasec (2017), esta pesquisa atualizou o diagnóstico nele descrito para o ano de 2017, apresentando seus resultados em dois itens (i) diagnóstico da arborização do campus - avaliado de forma quantiqualitativa e (ii) programa de controle e monitoramento parcial da subárea 1 , com uso do mapeamento digital.

\section{RESULTADOS E DISCUSSÃO}

Neste trabalho, o mapeamento arbóreo in loco foi realizado em todo o campus, resultando em uma listagem numérica sequencial dos indivíduos e suas coordenadas geográficas. O diagnóstico com o posterior monitoramento e medidas, foi realizado em uma das 
subáreas, selecionada aleatoriamente (subárea 1), que possui cerca de $18.197 \mathrm{~m}^{2}$ e corresponde a $14,28 \%$ da área total da UESPI (Tabela 1).

Tabela 1. Número, área em metros quadrados e em \% da área total das subáreas do campus Poeta Torquato Neto da UESPI, em Teresina, Piauí.

Table 1. Number, area in square meters and in \% of the total area of the sub-areas of the UESPI Poeta Torquato Neto campus, in Teresina, Piauí

\begin{tabular}{c|c|c}
\hline $\mathbf{N}^{\circ}$ da subárea & Área $\left(\mathbf{m}^{\mathbf{2}}\right)$ & \% da área total \\
\hline $1^{*}$ & 18.197 & 14,28 \\
\hline 2 & 45.555 & 35,75 \\
\hline 3 & 20.572 & 16,15 \\
\hline 4 & 13.891 & 10,90 \\
\hline 5 & 24.859 & 19,50 \\
\hline 6 & 4.369 & 3,42 \\
\hline Totais & $\mathbf{1 2 7 , 4 4 3}$ & $\mathbf{1 0 0 , 0 0}$ \\
\hline
\end{tabular}

Nota: * Área utilizada para o estudo.

\section{Diagnóstico da arborização do campus}

Por meio do levantamento realizado, foi possível constatar que o número total de indivíduos arbóreos na área de estudo teve aumento em comparação ao estudo de Rasec (2017), que apontou 529 indivíduos no campus (tendo sido 38 identificados em nível de espécie, seis identificados em nível de gênero e dois em nível de família), um acréscimo de 73 indivíduos (Tabela 2).

Tabela 2. Número de indivíduos arbóreos e de espécies botânicas em comparação entre estudos do campus Poeta Torquato Neto da UESPI, em Teresina, Piauí

Table 2. Number of arboreal individuals and botanical species in comparison between the studies from the Poeta Torquato Neto campus at UESPI, in Teresina, Piauí

\begin{tabular}{c|c|c|c}
\hline \multicolumn{2}{c|}{ Rasec (2017) } & \multicolumn{2}{c}{ Dados atuais (2019) } \\
\hline № de & № de & № de & № de \\
Indivíduos & Espécies & Indivíduos & Espécies \\
Arbóreos & Botânicas & Arbóreos & Botânicas \\
\hline 529 & 46 & 602 & 49 \\
\hline
\end{tabular}

Nesta pesquisa, todos os indivíduos arbóreos foram identificados em nível de espécie, com as devidas adequações relativas à identificação por gênero e família da pesquisa anterior. Três novas espécies encontram-se inseridas na flora do campus: Cordia sebestena L. (córdiade-flores-laranjas), com quatro indivíduos; Calotropis procera (Aiton) W.T.Aiton (algodão-de- 
seda), com dois indivíduos e Phoenix roebelenii O'Brien (tamareira-anã), com seis indivíduos. Por serem plantas jovens, justifica-se sua inexistência no primeiro trabalho.

Dentre as espécies mapeadas, a mais abundante continua sendo a Mangifera indica L. (mangueira), estando presente em todas as subáreas, com 169 indivíduos, correspondendo a aproximadamente $28,4 \%$ do total (Tabela 3). Em outras instituições de ensino superior, como a Universidade Federal de Mato Grosso (UFMT), a espécie aparece como a segunda mais abundante (PATRICIO, 2017) e na Universidade Federal do Rio Grande do Norte (UFRN), a terceira com maior ocorrência (MACÊDO; LISBOA; CARVALHO, 2012). Anacadium occidentale L. (cajueiro) se apresenta na mesma posição de frequência da UFRN, estando também na segunda posição (MACÊDO; LISBOA; CARVALHO, 2012).

Tabela 3. Espécies mais abundantes e menos abundantes em comparação de estudos, no campus Poeta Torquato Neto, Teresina, Piauí

Table 3. Species more abundant and less abundant in comparison studies on the campus poet Torquato Neto, Teresina, Piauí

\begin{tabular}{l|c|c|c|c}
\hline \multirow{2}{*}{ Espécies } & \multicolumn{2}{c}{ Rasec (2017) } & \multicolumn{2}{c}{ Dados atuais } \\
\cline { 2 - 5 } & Quant. & $\%$ & Quant. & $\%$ \\
\hline Mangifera indica L. & 168 & $31,6 \%$ & 169 & $28,308 \%$ \\
\hline Azadirachta indica A. Juss. & 82 & $15,4 \%$ & 130 & $21,776 \%$ \\
\hline Anacardium occidentale L. & 42 & $7,9 \%$ & 40 & $6,700 \%$ \\
\hline Artocarpus heterophyllus Lam. & 1 & $0,2 \%$ & 1 & $0,168 \%$ \\
\hline Cenostigma macrophyllum Tul. & 1 & $0,2 \%$ & 1 & $0,168 \%$ \\
\hline Morinda citrifolia L. & 1 & $0,2 \%$ & 1 & $0,168 \%$ \\
\hline
\end{tabular}

As espécies com as maiores frequências correspondem aos indivíduos exóticos Mangifera indica L. e Azadirachta indica A. Juss, ambas de origem indiana, totalizando 50,084\% do total, mais da metade da flora uespiana. A elevada frequência da Mangifera indica L. pode ser resultado do uso anterior da área, que era um grande sítio tendo sido arborizado por interesse dos proprietários. Na situação atual, estes indivíduos arbóreos podem provocar problemas nas áreas de estacionamento, pois a queda de frutos ocasiona danos aos veículos.

Vale ressaltar o considerável aumento de indivíduos de Azadirachta indica L. (nim indiano ou neem), 48 indivíduos, que se encontram até então ausente apenas na subárea 4. Essa espécie foi introduzida no Brasil na década de 80 , em razão do seu rápido crescimento, e sua capacidade de desenvolver-se bem em regiões semiáridas (devido à resistência à seca e a temperaturas elevadas). No entanto, é uma invasora e termina inibindo outras espécies da região, além de ocasionar problemas para algumas espécies da fauna e em mananciais (UCHÔA, 2017). 
$\mathrm{Na}$ caracterização detalhada dos indivíduos existentes na subárea 1, quanto ao porte, verificou-se a predominância do porte pequeno, até $6 \mathrm{~m}$, em 96 dos 160 indivíduos arbóreos avaliados (Figura 7). Isso indica que correspondem a indivíduos jovens, e que, portanto, ainda não são constituídos de copas grandes e frondosas, o que prejudica na constituição da cobertura arbórea da UESPI. No entanto, com o devido monitoramento e controle poderão tornar-se indivíduos adultos com capacidade de sombreamento.

Figura 7. Representação da quantidade de indivíduos nos parâmetros de porte das árvores da subárea 1 do campus Torquato Neto, UESPI, Teresina, Piauí

Figure 7. Representation of the number of individuals in the tree size parameters of subarea 1 of the Torquato Neto campus, UESPI, Teresina, Piauí

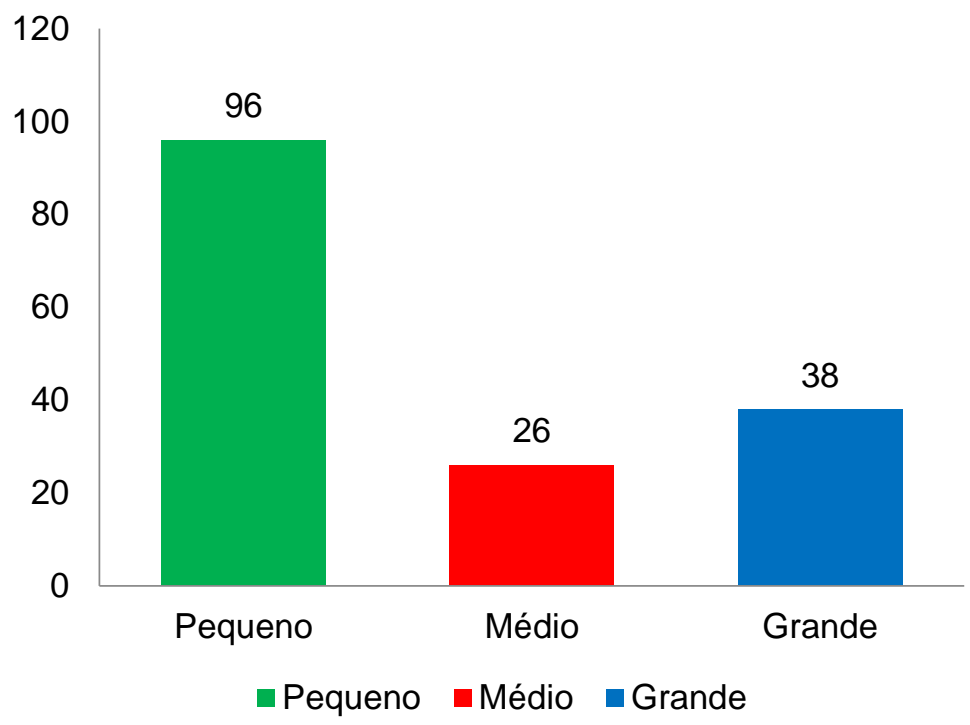

A maioria das árvores da subárea 1 (96 indivíduos) possuem menos de seis metros de altura, podendo assim afirmar que correspondem a indivíduos jovens, assim, ainda não são constituídos de copas grandes e frondosas, o que prejudica na constituição da cobertura arbórea da UESPI. No entanto, com o devido monitoramento e controle poderão tornar-se indivíduos adultos com capacidade de sombreamento.

Com relação ao estado fitossanitário, a maioria dos indivíduos arbóreos foram classificados com sintomas de doenças ou ataque leve de insetos (94\%), já com relação ao valor visual, constataram-se árvores com maior percentual de valor bom (81\%). Os danos devido a podas foram classificados, na grande maioria (95\%) como danos fracos e recuperáveis (Figura 8). 
Figura 8. Representação da quantidade de indivíduos nos parâmetros do Estado Fitossanitário (à esquerda), Danos devido de Poda (meio) e Valor Visual (à direita), das árvores da subárea 1 do campus Torquato Neto, UESPI, Teresina, Piauí

Figure 8. Representation of the number of individuals in the parameters of the Phytosanitary State (on the left), Damage due to Pruning (middle) and Visual Value (on the right), of the trees in subarea 1 of the Torquato Neto campus, UESPI, Teresina, Piauí

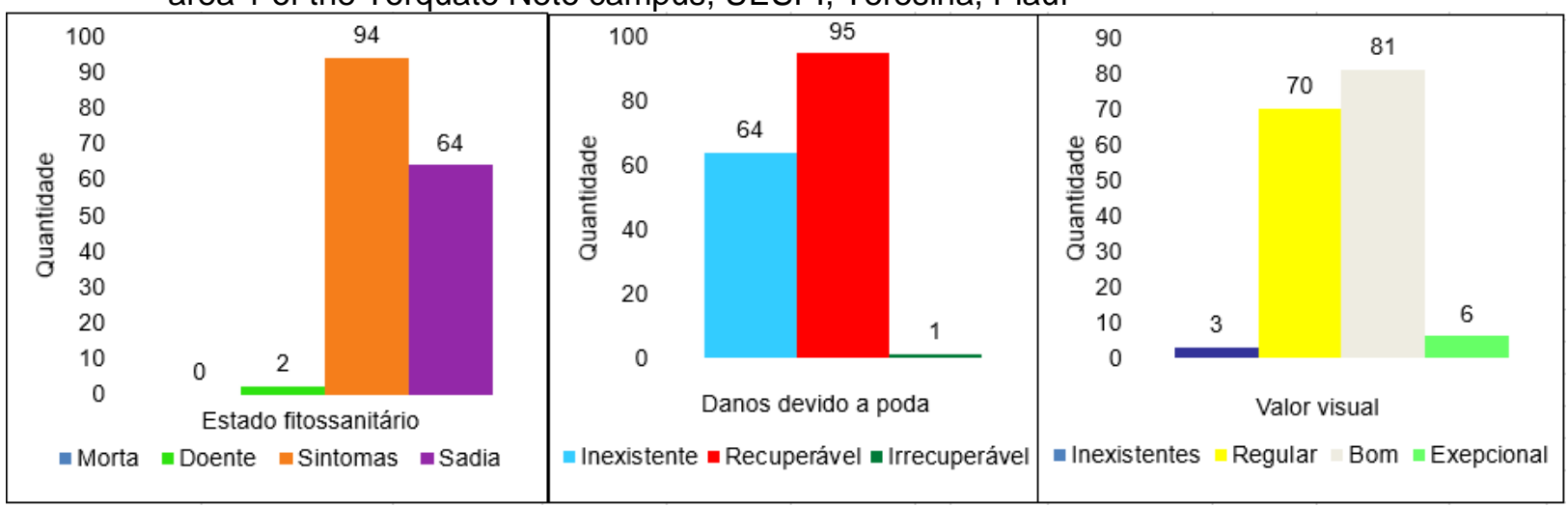

Sintomas de doenças ou ataque leve de insetos são encontrados em 94 indivíduos da subárea, número este que alerta a um imediato monitoramento adequado para reverter tal situação. O número de árvores sadias (64) na subárea, relaciona-se muito mais aos indivíduos serem jovens do que aos seus cuidados e monitoramento. Somente dois representantes arbóreos de espécies diferentes foram classificados como muito doentes: Psidium guajava L. (goiabeira) e Cocos nucifera L. (coqueiro), pois apresentavam fortes ataques por fitopatógenos o que alterou as qualidades de suas folhas e tronco.

Os danos devido a podas em 95 das árvores são fracos e recuperáveis, por não haver presença de depauperamento e visualização de brotamento nas regiões podadas, afetando apenas o aspecto estético, podendo ser recuperados através de intervenções planejadas e uso de equipamentos corretos. Macêdo, Lisboa e Carvalho (2012) identificaram o mesmo em sua pesquisa na UFRN, em que a maioria das necessidades de reparo nas árvores se deveu a ações inadequadas de poda, causando necrose de galhos e proporcionando um aspecto abjeto às árvores.

A análise dos aspectos relacionados a folha, flor e fruto, mostrou que a grande maioria dos indivíduos não estavam em época de floração e frutificação (Figura 9). 
Figura 9. Representação da quantidade de indivíduos nos parâmetros de presença de Mudança Foliar, Floração e Frutificação das árvores da subárea 1 do campus Torquato Neto, UESPI, Teresina, Piauí.

Figure 9. Representation of the number of individuals in the parameters of presence of Leaf Change, Flowering and Fruiting of trees in subarea 1 of the Torquato Neto campus, UESPI, Teresina, Piauí.

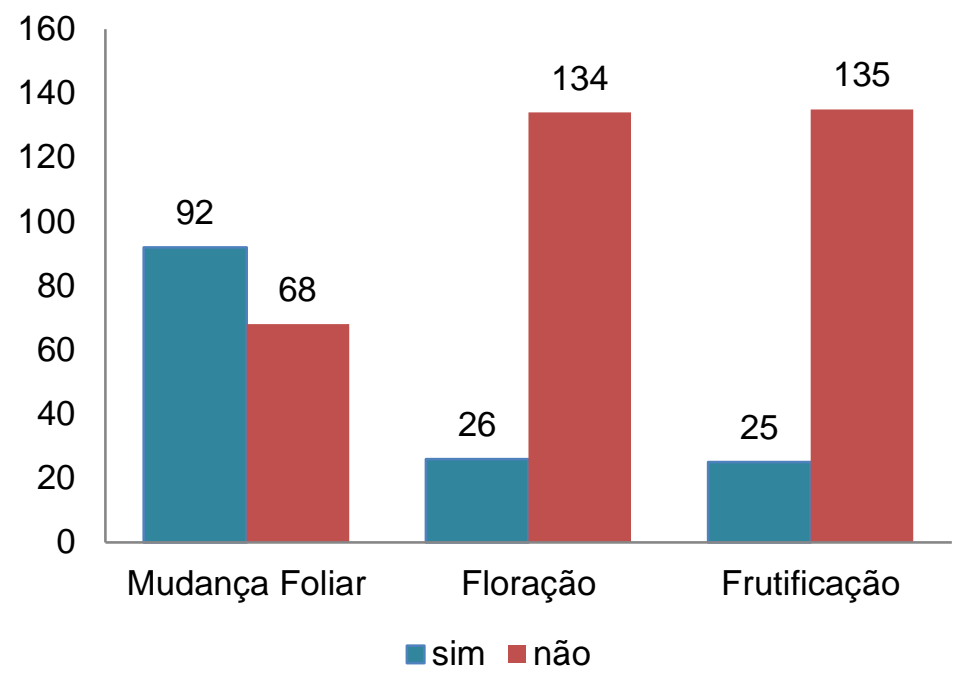

Os indivíduos da subárea 1 possuem em sua maior parte mudança foliar (92 árvores), e no mês correspondente ao diagnóstico, somente 26 indivíduos arbóreos estavam floridos, enquanto 25 continham frutificação.

\section{Programa de controle e monitoramento}

A subárea 1, como já mencionada, funcionou como um teste parcial para o monitoramento apresentado nesse estudo. Com um total de 160 indivíduos, o diagnóstico contou com três orientações: a necessidade de poda, cuidados fitossanitários e a remoção/substituição.

Para atender tais orientações se fez necessário uma parceria junto à Prefeitura Universitária, tanto em relação aos recursos materiais a serem utilizado para o teste (tesoura e serrotes de poda e equipamento de proteção individual - EPI's), quanto aos recursos humanos (colaboradores que iriam apoiar as ações de poda, remoção e plantio), na qual foi cedido um funcionário da instituição.

A primeira intervenção parcial foi à substituição de indivíduos de uma das espécies exóticas, a Azadirachta indica A. Juss. Nesta ação, optou-se por remover os indivíduos de menor porte pela facilidade de retirada do solo. Todas as mudas foram adquiridas através de doação pelo Viveiro Municipal de responsabilidade da Prefeitura de Teresina, localizada no Jardim Botânico da Cidade, no bairro Mocambinho. As mudas foram produzidas neste viveiro em espaço aberto, apresentando qualidades satisfatórias para o plantio (Figura 10). 
Figura 10. Produção de mudas no viveiro Municipal no Jardim Botânico de Teresina.

Figure 10. Seedling production at the Municipal nursery at Jardim Botânico of Teresina.
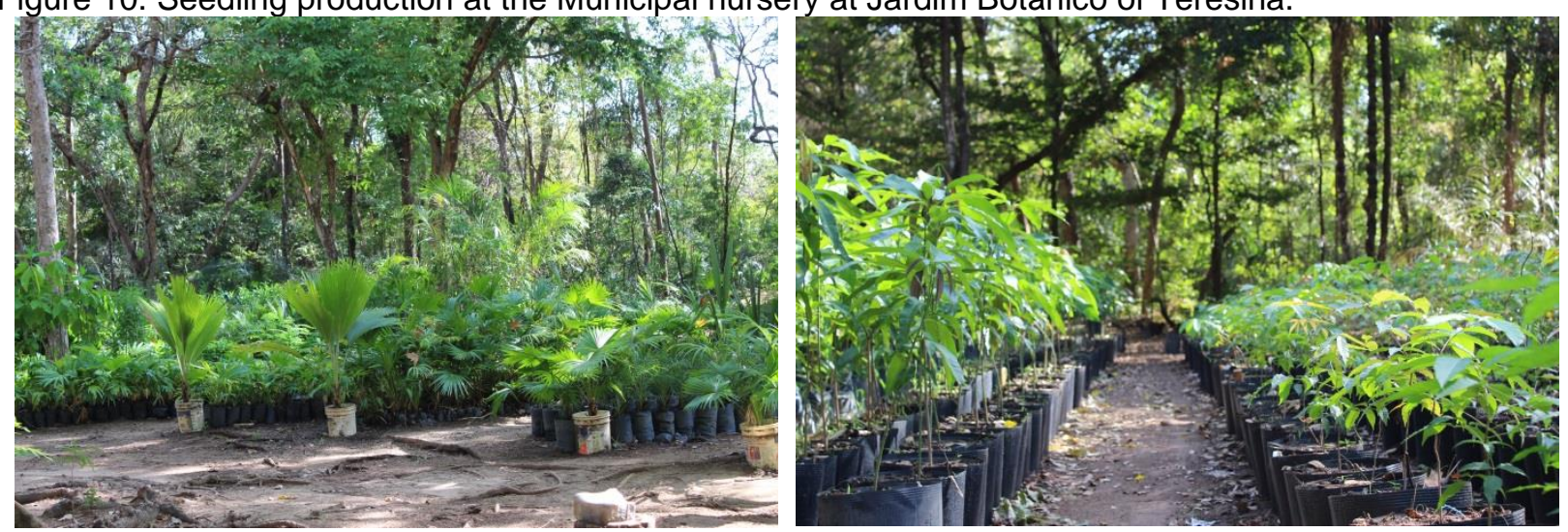

Fonte: SILVA, A. G., 2019.

Para uma adequada arborização deve-se respeitar o contexto ambiental da cidade, priorizando o plantio de espécies nativas que valorizem a identidade do bioma no qual se insere, desse modo, a fauna será atraída e a flora irá ser polinizada, bem como ocorrerá o fluxo gênico entre as espécies (FARIA; SOUSA; MIRANDA, 2014). Neste viveiro foram selecionados, prioritariamente, indivíduos de espécies nativas, representados por mudas de melhor qualidade (tanto em porte quanto em formação radicular), prontas para plantio. Foram angariadas 25 mudas de sete espécies, sendo 6 nativas e 1 exótica (para uso em áreas ajardinadas) (Tabela 4).

Tabela 4. Nome científico e comum das espécies de mudas recebidas do Viveiro Municipal de Teresina PI

Table 4. Scientific and common name of the seedling species received from the Municipal Nursery of Teresina - PI

\begin{tabular}{l|c|c}
\multicolumn{1}{c|}{ Nomes científicos } & Nome comum & Quant. \\
\hline Handroanthus sp & Ipê & 4 \\
\hline Cenostigma macrophyllum Tul. & Caneleiro & 5 \\
\hline Pachira aquatica Aubl. & Mamorana & 5 \\
\hline $\begin{array}{l}\text { Dypsis lutescens (H. Wendl.) Beentje \& J. } \\
\text { Dransf. }\end{array}$ & Areca-bambu & 2 \\
\hline Cassia fistula L. & Cássia-imperial & 2 \\
\hline Caesalpinia pulcherrima (L.) Sw & Flaboyanzinho & 5 \\
\hline Jasminum sp & Jasmim & 2 \\
\hline \multicolumn{2}{c}{ Total } & $\mathbf{2 5}$ \\
\hline
\end{tabular}

Para a realização das remoções optou-se pelo uso de ferramentas cortantes, em cortes bem próximos ao limite do caule com o solo seguida da retirada das raízes. Por conseguinte, foi realizada a umidificação do terreno e depois a escavação da cova. As mudas foram retiradas dos recipientes que as continham com a precaução de manter o torrão intacto até o plantio, com objetivo de não danificar as raízes, sendo, em todos os momentos do processo, o local definitivo encharcado para manter-se umedecido. Por fim, as mudas já plantadas, foram adicionadas um tutor, para melhor fixação e posteriormente irrigadas (Figura 11). 
Figura 11. Procedimentos realizados nas substituições e plantios de indivíduos, no Campus Poeta Torquato Neto, UESPI.

Figure 11. Procedures performed in replacing and planting individuals, at Campus Poeta Torquato Neto, UESPI.
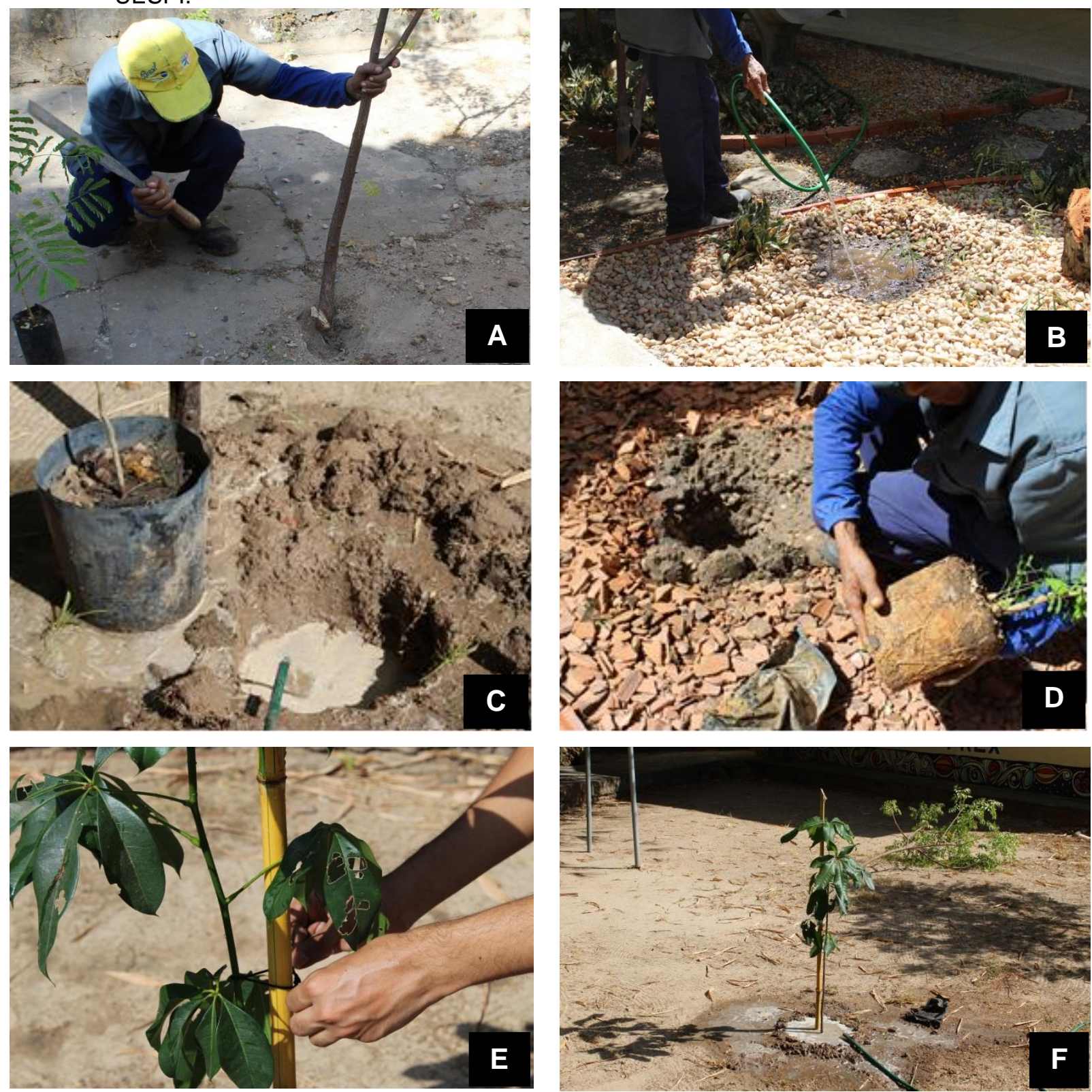

Legenda - A (Corte realizado próximo ao limite do caule com o solo); B (Umidificação do terreno); C (Manutenção do terreno encharcado); D (Cuidados com o torrão); E (Adicionando um tutor); F (Irrigação após o plantio).

O plantio necessitou de cuidados específicos para a obtenção do sucesso de pega e crescimento das mudas, devido ter ocorrido em um período de clima quente e seco. Algumas dificuldades apresentaram-se, a primeira delas estava relacionada à indisponibilidade de água (sistema de canalização) próxima aos canteiros já existentes no campus. Nesse caso, foi preciso utilizar mangueira e por vezes baldes para o transporte d'água. Essa dificuldade permanece na manutenção futura desses indivíduos. 
Durante a atividade de remoção de indivíduos da espécie Azadirachta indica A. Juss para a substituição por plantio de mudas de espécies nativas, houve resistência de setores da instituição ligados à coordenação dos cursos onde se encontravam algumas das retiradas, por entenderem que os indivíduos da espécie citada crescem mais rápido e promovem mais sombra para veículos. Nesta área realizou-se seis novos plantios, de um total de 10 planejados.

No entanto, outros setores foram atendidos somando um total de 15 substituições. As mudas que não puderam ser plantadas em consequência da dificuldade de remoção foram realocadas para ambientes sem cobertura arbórea.

Com os dez novos plantios realizados procurou-se atender espaços mais abertos e que necessitavam de maior sombreamento, como estacionamento e caminhos de pedestres.

Com relação à intervenção de poda, só foi possível sua realização em poucos indivíduos arbóreos, devido a indisponibilidade de equipamentos de poda, tanto serrotes quantos EPI's. Tendo sido realizada a chamada "poda de limpeza", a maioria para promover o levantamento da copa, onde são retirados os galhos mais próximos ao solo, que possam impedir a passagem de pessoas ou estacionamento de veículos, permitindo assim, somente o crescimento vertical da árvore (Figura 12).

Figura 12. Indivíduo arbóreo com indicação de poda de limpeza, Campus Poeta Torquato Neto, UESPI. Figure 12. Arboreal individual with indication of cleaning pruning, Campus Poeta Torquato Neto, UESPI.
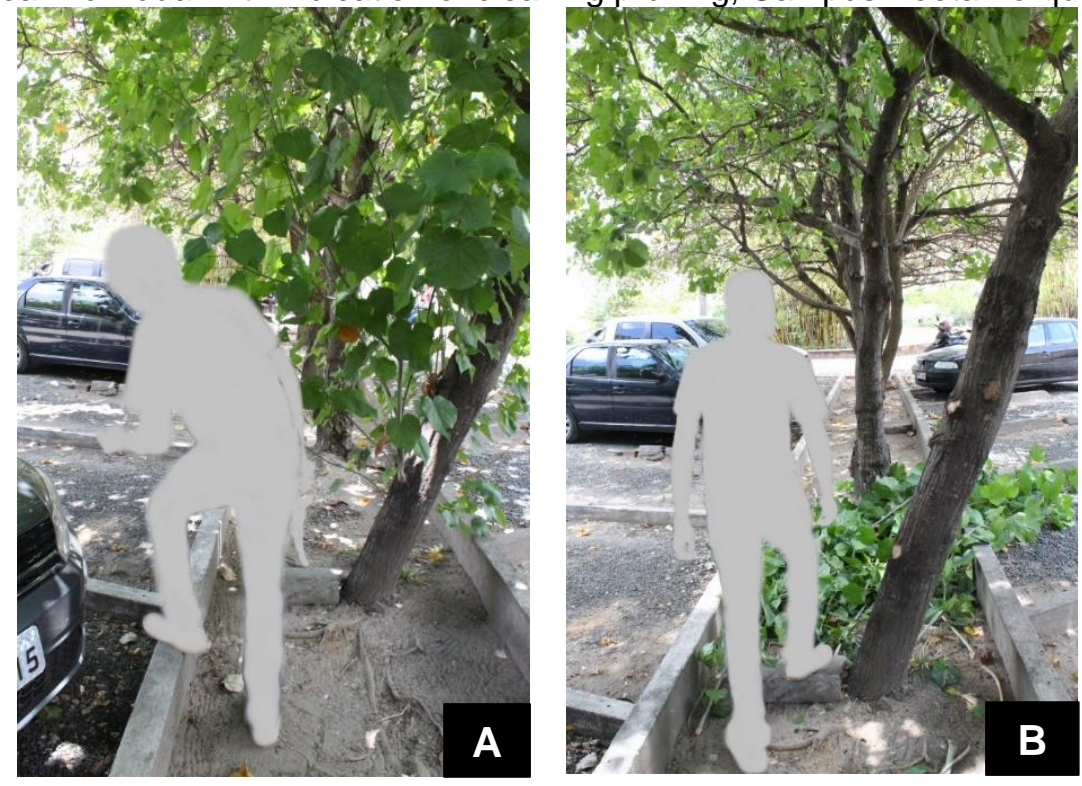

Legenda - Esquerda (poda de limpeza, para levantamento de copa, realizada em indivíduos da espécie Calotropis procera (Aiton) W.T.Aiton em área de estacionamento e passagem de pedestre); Direita (Após a poda de limpeza, facilidade em transitar e estacionar veículos).

Em relação aos cuidados fitossanitários, estes não puderam ser realizados, pois não houve disponibilidade dos materiais necessários pela instituição. Contudo, poderá ser realizado a posteriori, visto que tal orientação encontra-se na planilha de monitoramento, a qual foi entregue aos gestores da Prefeitura Universitária. 


\section{CONCLUSÕES}

A pesquisa indicou que houve um aumento no número de indivíduos arbóreos no campus no período de 2017 até 2019. As três espécies novas inseridas indicam uma discreta expansão da diversidade da flora uespiana, não ocorrendo mudanças nos três indivíduos mais frequentes. As espécies exóticas/invasoras têm substituído às espécies nativas em grande número, devendo ser imediata a remoção/substituição.

O mapeamento utilizando o programa Google Earth Pro demostrou-se atender todo o campus, permitindo inúmeras atualizações e facilitando os resultados do monitoramento. Com cada árvore identificada e mapeada, o controle e execução de medidas para mitigar possíveis danos às mesmas podem ser planejados em menor espaço temporal, podendo o monitoramento ser executado de forma regular, em períodos que variam de acordo com cada subárea.

Este estudo, realizado no Campus Poeta Torquato Neto da UESPI, pode servir como modelo para aplicação nos demais campi da IES, sendo uma importante ferramenta para o planejamento da arborização destes espaços, promovendo melhorias para o bem estar dos uespianos.

\section{REFERÊNCIAS}

ALBUQUERQUE, D. S.; SILVA, D. S.; KUHNEN, A. Preferências Ambientais e Possibilidades de Restauro Psicológico em Campi Universitários. Psicol. cienc. prof. [s/l], v.36, n.4, p.893-906, 2016.

BARBIERI, J. C. Gestão ambiental empresarial: conceitos, modelos e instrumentos - 4. ed. - São Paulo: Saraiva, 2016.

BARGOS, D. C.; MATIAS, L. F. Áreas verdes urbanas: Um estudo de revisão e propostas conceituais. Revista da Sociedade Brasileira de Arborização Urbana. Piracicaba - SP, v. 6, n. 3, p.172-188, 2011.

BASTOS, E. A. Boletim Agrometeorológico de 2015 para o Município de Teresina, Piauí. Embrapa Meio-Norte, Teresina. 2016.

BERTRAND, C.; BERTRAND, G. Une géographie traversière: l'environnement à travers territoires et temporalités. Paris: Éditions Arguments, 2002. 311p.

BIONDI, D. Floresta urbana: conceitos e terminologias. Floresta Urbana. Curitiba: In BIONDI, p. 11-27, 2015.

BRANDÃO, I. M.; GOMES, L. B.; SILVA, N. C. A. dos R.; FERRARO, A. C.; SILVA, A. G. da; GONÇALVES, F. G. Análise quali-quantitativa da arborização urbana do município de São João Evangelista - MG. Revista da Sociedade Brasileira de Arborização Urbana. Piracicaba - SP, v.6, n.4, p.158-174, 2011. 
FARIA, R. F. da; SOUSA, V. R. de; MIRANDA, S. do. C. de. Arborização urbana da cidade de Itapuranga, Goiás. Revista da Sociedade Brasileira de Arborização Urbana. Piracicaba - SP, v.9, n.2, p.101-117, 2014.

IBGE, Instituto Brasileiro de Geografia e Estatística. Brasil em síntese: território. 2017. Disponível: https://brasilemsintese.ibge.gov.br/territorio.html. Acessado em 20 dez. 2018.

KALLAS, L. M. E. Desenhando com o clima e a vegetação: Um estudo de caso do loteamento HBB em Teresina-PI. Dissertação (Mestrado em Arquitetura e Urbanismo) Faculdade de Arquitetura e Urbanismo, Universidade de Brasília, Brasília, 2008.

LABAKI, L. C.; SANTOS, R. F. dos; BUENO-BERTHOLOMEI, C. L.; ABREU, L. V. de. Vegetação e conforto térmico em espaços urbanos abertos. Revista Fórum Patrimônio. Belo Horizonte - MG, v.4, n.1, p.23-42, 2011.

LO CASTRO, J.K.; MIOTTO, J.L.; DEANGELIS, B.L.D.; CAXAMBU, G.M. Avaliação do uso sustentável da arborização urbana no município de Cafeara, Paraná. Ciênc. Florest. v. 27 n.2 Santa Maria, 2017.

LUPPI, A.S.L.; SANTOS, A. R.; EUGENIO, F, C. FEITOSA, L.S. Utilização de Geotecnologia para o Mapeamento de Áreas de Preservação Permanente no Município de João Neiva, ES. Revista Floresta e Ambiente, Seropédica, v. 22, n.1, p. 13-22, 2015.

MACÊDO, B. R. M.; LISBOA, C. M. C. A.; CARVALHO, F. G. Diagnóstico e Diretrizes para a Arborização do. Campus Central da Universidade Federal do Rio Grande do Norte.

Revista da Sociedade Brasileira de Arborização Urbana, Piracicaba - SP, v.7, n.1, p. 35-51, 2012.

MORAES, A. L.; MACHADO, R. R. B. A arborização urbana do município de Timon/MA: inventário da diversidade e diagnóstico quali-quantitativo. Revista da Sociedade Brasileira de Arborização Urbana, Piracicaba - SP, v.9, n.4, p.80-98, 2014.

OLIVEIRA, F. C. de; MAUES, M. M. Fenologia qualitativa de floração, frutificação e mudança foliar em castanha-do-brasil (Bertholletia excelsa), Belém, (PA). Embrapa Amazônia Oriental (CPATU), Seminário De Iniciação Científica. Belém, p. 45.

PATRICIO, P.P.M. Florística e Diagnóstico da Arborização da Universidade Federal de Mato Grosso, Campus Cuiabá. 2017. 106p. Dissertação (Pós-Graduação em Ciências Florestais e Ambientais) Programa de Pós-Graduação em Ciências Florestais e Ambientais, Universidade Federal de Mato Grosso, Faculdade de Engenharia Florestal, Cuiabá, Mato Grosso, 2017.

RASEC, A. S. S. Evolução Temporal da Paisagem do Campus Poeta Torquato Neto da UESPI. $15 f$ Dissertação Trabalho de Conclusão de Curso (Graduação em Bacharelado em Ciências Biológicas) - Universidade Estadual do Piauí, Teresina, 2017.

SABBAGH, R. Arborização urbana no bairro Mario Dedini em Piracicaba. Revista da Sociedade Brasileira de Arborização Urbana. Piracicaba - SP, v.6, n.4, p.90-106, 201 UCHÔA, G. Árvores nativas perdem espaço dentro do arranjo de desenvolvimento da cidade. Portal O Dia, 2017. Disponível em: http://www.sbau.org.br/2017/04/25/teresina-arvores-nativasperdem-espaco-dentro-arranjo-de-desenvolvimento-da-cidade/. Acesso em: 11 out. 2019. 